\title{
Synthesis and Characterization of Magnetic Xerogel Monolith as an Adsorbent for As(V) Removal from Groundwater
}

\author{
Sasirot Khamkure ${ }^{1, *}$, Sofía Esperanza Garrido-Hoyos ${ }^{2}$, Prócoro Gamero-Melo ${ }^{3}$ and Audberto Reyes-Rosas ${ }^{4}$ \\ 1 CONACyT-Instituto Mexicano de Tecnología del Agua, Jiutepec, Morelos 62550, Mexico \\ 2 Instituto Mexicano de Tecnología del Agua, Jiutepec, Morelos 62550, Mexico; sgarrido@tlaloc.imta.mx \\ 3 CINVESTAV IPN-Unidad Saltillo, Ramos Arizpe, Coahuila 25900, Mexico; procoro.gamero@cinvestav.edu.mx \\ 4 Centro de Investigación en Ciencias-IICBA, Universidad Autónoma del Estado de Morelos, Cuernavaca, \\ Morelos 62209, Mexico; reyes2709@gmail.com \\ * Correspondence: sasirot.khamkure@posgrado.imta.edu.mx
}

Citation: Khamkure, S.; Garrido-Hoyos, S.E.; Gamero-Melo, P.; Reyes-Rosas, A. Synthesis and Characterization of Magnetic Xerogel Monolith as an Adsorbent for As(V) Removal from Groundwater. Processes 2021, 9, 386. https:// doi.org/10.3390/pr9020386

Academic Editor: María V.

López-Ramón

Received: 18 January 2021

Accepted: 12 February 2021

Published: 20 February 2021

Publisher's Note: MDPI stays neutral with regard to jurisdictional claims in published maps and institutional affiliations.

Copyright: (C) 2021 by the authors Licensee MDPI, Basel, Switzerland. This article is an open access article distributed under the terms and conditions of the Creative Commons Attribution (CC BY) license (https:/ / creativecommons.org/licenses/by/ $4.0 /)$.

\begin{abstract}
Arsenic contamination of groundwater is still a global problem due to the toxicity at low dose on human health confirmed by epidemiological studies. Magnetic xerogel monoliths (MXs) were synthesized by the sol-gel polymerization using resorcinol, formaldehyde, alkaline catalyst and magnetite. The varying molar ratios of magnetite and resorcinol $(M / R)$ in the gel were evaluated for $\mathrm{As}(\mathrm{V})$ removal from groundwater. The surface chemistry, structure and morphology of MXs related to arsenic adsorption were characterized by X-ray diffraction, scanning electron microscopy, energy-dispersive X-ray spectroscopy, Fourier transform infrared spectroscopy and point of zero charge. Batch adsorption experiments were carried out to investigate the effects of Fe contents, initial $\mathrm{pH}$ and adsorbent dose on $\mathrm{As}(\mathrm{V})$ removal performance. The MXs with molar ratio of $\mathrm{M} / \mathrm{R}$ at 0.15 gave the maximum $\mathrm{As}(\mathrm{V})$ adsorption capacity and removal with values of $62.8 \mu \mathrm{g} / \mathrm{g}$ and $86.7 \%$, respectively. The adsorption data were well described by the Elovich equation of the kinetic model and the Freundlich isotherm. The thermodynamic studies demonstrated that the adsorption process was endothermic and spontaneous in nature. MXs showed to be a good alternative for $\mathrm{As}(\mathrm{V})$ removal from groundwater and achieving the efficient desorption, and thus fulfilled the Mexican standard for drinking water.
\end{abstract}

Keywords: adsorption; arsenic removal; groundwater; magnetic; xerogel

\section{Introduction}

Water is an essential requirement for human beings and living things. The quality of water resources is altered by the source of natural and anthropogenic pollution. The contamination of aqueous effluents is a serious problem that directly and indirectly alters the balance of different ecosystems and affects human health. Arsenic is one of substances with potential health risk due to its toxicology and carcinogenicity. Mostly arsenic is found in groundwater caused from its distribution to the earth's crust in the naturally occurring source by geology, hydrogeology, and geochemistry especially in arid and semi-arid regions [1,2]. The main anthropogenic sources of arsenic are caused from mining, smelting and ore beneficiation processes, petroleum refining, coal burning and industries of agricultural chemicals (pesticides and insecticides) [2,3]. Arsenic in natural water is mostly presented in inorganic forms, such as arsenate As(V) and arsenite As(III). $\mathrm{As}(\mathrm{V})$ and As(III) can be found in well oxygenated (aerobic) surface water and anaerobic groundwater, respectively. Arsenic contamination of groundwater is still a health problem in the world. Millions of people in Argentina, Bangladesh, Chile, China, Hungary, India, Mexico, Mongolia, Taiwan, Thailand, Vietnam, and the USA directly affect this issue [4,5]. The health risk assessment for human exposure is concerned due to the distribution of inorganic arsenic species through drinking water. Especially the vulnerable and sensitive groups like children, pregnant women, and newborns, can lead to significant not only 
health issues but also neurotoxic effects, immunotoxic events, genotoxicity and cardiac and renal effects $[6,7]$.

The arsenic problem in Mexico dates from the 1960s, until now it has been detected that arsenic contamination in the water supply from aquifers of various areas for example region of northern, central and west-central Mexico [8]. Moreover, about 75 percent of the total population utilizes groundwater for daily drinking water [1]. Due to the arsenic toxicity at low dose and epidemiological studies of the effects of arsenic on human health, therefore, the permissible maximum contaminant level of arsenic in drinking water of Mexican standard (NOM-127-SSA1-1994) and World Health Organization (WHO) are 25 and $10 \mu \mathrm{g} / \mathrm{L}$, respectively.

Various techniques for arsenic removal methods and their technological developments from water and wastewater treatments have been studied such as membrane filtration [4,9], biological processes [10], coagulation-flocculation [11], ion exchange [12,13], and adsorption [14-16]. Within these methods, the adsorption has been widely extended as a competitive application for the water and wastewater treatment. It is considered a good option because of cost-effective technology, high efficiency, easy access to materials, easy operating system, regeneration ability and no sludge production or generation of toxic byproducts [3,5,17].

The organic gels are mesoporous materials obtained by sol-gel polymerization of resorcinol (R) and formaldehyde (F) in deionized water (W), using acidic or alkaline catalyst (C) following the procedure described by Pekala [18]. Resorcinol formaldehyde (RF) gels have attracted attention because of the properties of chemical stability, texture characteristics, resistance in mechanics and the possibility to obtain different shapes of resulting products. The useful properties of this material are due to high porosity, surface area and pore volume. Moreover, the variation of the synthesis and processing conditions such as reactant concentrations, catalyst solution, $\mathrm{pH}$, gelation and curing can be modified to control and affect their properties and structures of the RF gels directly [19]. Although the small quantity of catalyst is used for the polymerization of $R$ and $F$, the influence of R/C is the one factor that controls porous structure, surface area and porosity of RF gel [20]. The mesoporosity of the RF gels are enlarged with the increasing molar ratio of R/C [21-23].

The specific applications of RF gel are for electrodes batteries, supercapacitors, catalysts, adsorbents, molecular sieves, $\mathrm{CO}_{2}$ capture and pollutant removal from water and wastewater treatment [24-28]. The doping with metal and metal oxides is interesting especially for adsorption and catalysis applications [29-34]. The adsorption from aqueous solution by using RF gels have been investigated such as the removal of $\mathrm{Cr}(\mathrm{VI})$ by irondoped RF aerogels [29], $\mathrm{SiO}_{2}-\mathrm{ZrO}_{2}$ xerogel for the removal of organic dye [26], $\mathrm{RF}$ carbon xerogel as selective adsorbent of carbon dioxide on biogas [27], hydrophobic silica based aerogels and xerogels for removal of toxic organic compounds [35], carbon xerogels using tannic acid- $\mathrm{RF}$ resin for $\mathrm{Pb}$ removal [36], heavy metal ions $\left(\mathrm{Ni}^{2+}, \mathrm{Cu}^{2+}\right.$, and $\left.\mathrm{Zn}^{2+}\right)$ removal using carbon aerogels and xerogels [25], and arsenic (III) removal on carbon cryogel/ceria nanocomposite [30] and the core-shell structured RF/PVA nanofibers [37]. Several RF gels have been synthesized for studying the adsorption of contaminants in water systems.

The material development for arsenic removal, can be prepared with different (pellet or cylinder), in addition, be easily recovered from the aqueous solution as in the case of monolithic gels with ferromagnetic particles. The magnetic xerogel monoliths (MXs) were synthesized with the varying molar ratio of magnetite for use as an adsorbent in the removal of $A s(V)$. The synthesized materials were characterized with various techniques. Adsorption experiment was studied with the concentration of $\mathrm{As}(\mathrm{V}) 100 \mu \mathrm{g} / \mathrm{L}$ of groundwater to determine the effects of $\mathrm{pH}$, Fe contents and adsorbent dosage. Adsorption kinetic, isotherm, thermodynamics and desorption were also investigated. Obtained experimental data on individual adsorption of arsenic with synthesized materials were fitted with several theoretical models and their capacity for arsenic adsorptions were discussed. The purpose of this study is to estimate the feasibility of using these materials as an alternative adsorbent material for the removal of arsenic in groundwater. 


\section{Materials and Methods}

\subsection{Materials}

All the reagents used to synthesize magnetic xerogels were analytical grade which were 1, 3-dihydroxybenzene $\mathrm{C}_{6} \mathrm{H}_{4}(\mathrm{OH})_{2}$ (Chemistry Meyer, Mexico City, Mexico), sodium carbonate $\mathrm{Na}_{2} \mathrm{CO}_{3}$ (J.T. Baker, Mexico City, Mexico), formaldehyde HCHO (J.T. Baker, Mexico City, Mexico), acetone $\left(\mathrm{CH}_{3}\right)_{2} \mathrm{CO}, 99.5 \%$ (J.T. Baker, Mexico City, Mexico) and magnetite $\mathrm{Fe}_{3} \mathrm{O}_{4}$ (Lanxess, García, Nuevo León, Mexico). The preparation of As(V) solution for batch adsorption experiment using sodium arsenate dibasic heptahydrate $\mathrm{HAsNa}_{2} \mathrm{O}_{4} \cdot 7 \mathrm{H}_{2} \mathrm{O}$ (Sigma-Aldrich, Toluca, Mexico State, Mexico).

\subsection{Synthesis of Magnetic Xerogel Monoliths}

The synthesis of MXs was attended to generate the incorporation and dispersion of magnetite in the RF gel structure with indirect sonication method before the process of gelation and curing. Due to formaldehyde is one chemical for gel preparation and its high reactivity, by the way it is possible to aid the precipitation of metal ions $\left(\mathrm{Fe}^{3+}\right)$ under metallic state that result in the agglomeration of metal and nonhomogeneous of gel properties [38]. The preparation of MXs was carried out following the method described by Khamkure et al. [20]. In this synthesis, the molar ratios used were: $R / F=0.5, R / C=100$ and $\mathrm{R} / \mathrm{W}=0.04$. The $\mathrm{MXs}$ were prepared varying the Fe contents of magnetite $(\mathrm{M})$ and their molar ratios $(\mathrm{M} / \mathrm{R})$ were $0.05,0.1,0.15$, and 0.2 . The indirect sonication method applied was the ultrasonic energy transmitted from the probe through water and tubes for homogenization and deagglomeration magnetite particles into RF aqueous solution. After sonication, the MXs were produced, and they could be checked by visual observation. The glass tubes were cured 3 days at $80{ }^{\circ} \mathrm{C}$, followed with 2 days of solvent exchange at room temperature by using a shaking water bath (BS-11; Lab companion). After vacuum filtration, the replacement of fresh solvent was applied daily. Then the drying gels were applied for 3 days in an oven at $80^{\circ} \mathrm{C}$. Finally, materials obtained were black in color and labelled as magnetic xerogel monoliths (MXs).

\subsection{Characterization of Magnetic Xerogel Monoliths}

The synthesized materials were characterized by X-ray diffraction (XRD), scanning electron microscopy (SEM), energy-dispersive X-ray spectroscopy (EDX), Fourier transform infrared spectroscopy (FTIR) and measurement of the $\mathrm{pH}$ at the point of zero charge $\left(\mathrm{pH}_{\mathrm{PZC}}\right)$ and the isoelectric point (IEP). The Fe contents in the synthesized MXs were analyzed by using an atomic absorption spectrometer Perkin Elmer Analyst 400 (Shelton, Connecticut, USA). XRD was performed on a D8 ADVANCE model of the Bruker brand (Karisruhe, Germany). The SEM and EDX techniques were analyzed by using a JSMIT300 (Tokyo, Japan), which were coated with gold. Surface chemistry of materials was obtained by $\mathrm{pH}_{\mathrm{PZC}}$ and the isoelectric point IEP, which is determined by potentiometric titrations and electrokinetic measurements, respectively, following the method described by Amaringo and Anaguano [39]. A zeta potential analyzer Microtrac PMX 500 (Meerbuch, Germany) was used to measure the zeta potential to determine IEP and pH meter Orion Star A211 (Thermo Scientific, USA) was used to measure $\mathrm{pH}$ solution with a $\mathrm{pH}$ range (2-10). FTIR was carried out through a spectrophotometer Shimadzu IRAffinity-1S (Shimadzu Corp., Japan) to determine the surface functional groups that are in the synthesized organic xerogels. The FTIR analysis of the three samples was carried out before and after exposure of As. The samples in powder form were dried overnight at $60{ }^{\circ} \mathrm{C}$ before placement in a desiccator awaiting analysis. The infrared spectra results were acquired between the wave number of $400-4000 \mathrm{~cm}^{-1}$ with 45 scans per sample. Attenuated total reflection (ATR, Specac; GS10800) with the crystal puck (type IIIa monocrystalline diamond) was installed and fitted to the optical unit of the FTIR system. 


\subsection{Batch Adsorption Experiments for $A s(V)$}

In this experiment, the groundwater sample was obtained from a water well in Morelos, Mexico and was analyzed as stated by a standard method [40]. The batch adsorption was performed using a solution of $\mathrm{As}(\mathrm{V})$ by diluting to a required concentration with groundwater. All the experiments, MXs were applied $100 \mathrm{mg}$ (dose $2 \mathrm{~g} / \mathrm{L}$ ) with $50 \mathrm{~mL}$ of $\mathrm{As}(\mathrm{V})$ solution in the centrifuge tube, except the study of adsorbent dose. All the solution tubes were shaken by using a shaking water bath at $150 \mathrm{rpm}$ at room temperature $\left(25 \pm 2{ }^{\circ} \mathrm{C}\right)$. Afterwards, each solution was filtered through a vacuum pump with $0.45 \mu \mathrm{m}$ of the cellulose nitrate membrane filters (Whatman) to separate the solid from the supernatant. The residual concentration of $\mathrm{As}(\mathrm{V})$ was performed on an Inductively coupled plasma atomic emission spectroscopy (ICP-AES), OPTIMA 3200 DV model Perkin Elmer brand, using the hydride generation method with $\mathrm{KI}$ and Ascorbic Acid as pre-reducing agents.

The batch adsorption experiments were conducted and evaluated the effect of $\mathrm{Fe}$ contents of eight samples of MXs. For studying the effect of $\mathrm{pH}$ in aqueous solution, the initial $\mathrm{pH}$ of the solutions was adjusted from 2 to 10 by using $0.1 \mathrm{M} \mathrm{HCl}$ and $0.1 \mathrm{M} \mathrm{NaOH}$ solutions. Effect of adsorbent dosage was studied to determine the optimum dosage of adsorbent to the percentage of arsenic removal and was varied with different dosage from 0.5 to $4 \mathrm{~g} / \mathrm{L}$. The adsorption kinetics was performed for the removal As $(\mathrm{V})$ with respect to different contact time intervals. The isotherm adsorption experiment was studied by varying initial $\mathrm{As}(\mathrm{V})$ concentration from 25 to $175 \mathrm{mg} / \mathrm{L}$. Thermodynamic analysis was also investigated with 3 different temperatures which are 25,35 , and $45^{\circ} \mathrm{C}$.

All the results from the experiment were calculated and evaluated as the percentage of arsenic removal and the adsorption capacity. The removal efficiency of $\mathrm{As}(\mathrm{V})$ can be calculated as follows:

$$
\text { \%removal }=\frac{C_{0}-C_{e}}{C_{0}} \times 100
$$

where $C_{0}$ and $C_{\mathrm{e}}$ are the concentration of $\mathrm{As}(\mathrm{V})$ in aqueous solution before and after adsorption $(\mathrm{mg} / \mathrm{L})$, respectively. The $\mathrm{As}(\mathrm{V})$ adsorption capacity, $q_{e}(\mathrm{mg} / \mathrm{g})$ is defined as follows:

$$
q_{e}=\frac{C_{0}-C_{e}}{m} \times V
$$

where $V$ is the volume of aqueous solution (L) and $m$ is the mass of MXs (g).

Previous studies have been reported that an invaluable nonlinear regression analysis is a better way to obtain the equilibrium isotherm parameters and coefficients for describing the adsorption [41-43]. Therefore, in this study the adsorption kinetic and isotherm were used for mathematical description and empirical models that fit to the experimental data. The models and errors of analysis of these studied data were applied to a nonlinear least squares regression method using the QtiPlot v0.9.8.3 program. The correlation coefficient $\left(R^{2}\right)$, the residual sum of squares (RSS) also known as the sum of squared estimate of errors (SSE) and the root mean square error (RMSE) were calculated following the equations described by Hanbali et al. [44] to represent the compatibility of the model equations.

\subsection{Desorption Study}

Due to this research focuses on generating magnetic materials that can be easily recovered from the aqueous medium. The purpose of desorption study is important to evaluate the possibility for reusability and regenerability of the used material. Moreover, it is useful for practical applications of this adsorbent in water and wastewater treatment.

The used material from kinetic study was applied to desorption process that had an initial $\mathrm{As}(\mathrm{V})$ concentration of $75 \mu \mathrm{g} / \mathrm{L}$. One hundred milligrams of As-adsorbed MXs was added in the centrifuge tube with $50 \mathrm{ml}$ of alkaline solution with different time interval and concentrations. The plastic tubes were centrifuged using centrifuge (Eppendorf; model 
$5804)$ at $200 \mathrm{rpm}$ at room temperature $\left(25 \pm 2{ }^{\circ} \mathrm{C}\right)$. The desorption efficiency of the MXs can be calculated [37] as follows:

$$
\text { Desorption efficiency }=\frac{\text { amount of metal desorbed }}{\text { amount of metal ions adsorbed }} \times 100 \text {. }
$$

\section{Results}

\subsection{Behavior of Fe Contents in Magnetic Xerogel Monoliths on As(V) Removal}

The MXs were prepared with different magnetite loadings into the xerogels and their molar ratios of $\mathrm{M} / \mathrm{R}$ were $0.05,0.1,0.15$, and 0.2 . The Fe contents in the synthesized MXs were determined using an atomic absorption spectrometer and are presented in Figure 1. It can be observed that percent of Fe contents increased continuously following the increase of molar ratios of $\mathrm{M} / \mathrm{R}(0.05$ to 0.2$)$ and were approximately five times on the increase from the molar ratio of $\mathrm{M} / \mathrm{R}$ at 0.05 to 0.15 .

The As removal of MXs prepared with molar ratio of M/R at 0.05 and 0.1 had similar percentages of Fe contents which were $2.73 \%$ and $3.99 \%$, respectively (Figure 1 ). The increase of the Fe contents at $14.27 \%$ was found to be significant, when it resulted in a high As removal (77.60\%). MXs synthesized with $M / R$ at 0.2 gave the lower of As removal $(57 \%)$ even contained the highest of the Fe contents $(16.47 \%)$. It can be explained that the higher Fe incorporation of RF polymer might affect the saturation of arsenic into active sites on the surface of MXs. Moreover, it can be explained that some magnetite particles were leached out during the process of solvent exchange with acetone due to their particles being unbound to the polymeric matrix during synthesis [29]. Therefore, the MXs with $\mathrm{M} / \mathrm{R}$ at 0.15 contained $14.27 \%$ of Fe contents was selected for characterization and applied for studying the batch adsorption for $\mathrm{As}(\mathrm{V})$ removal, which is shown later.

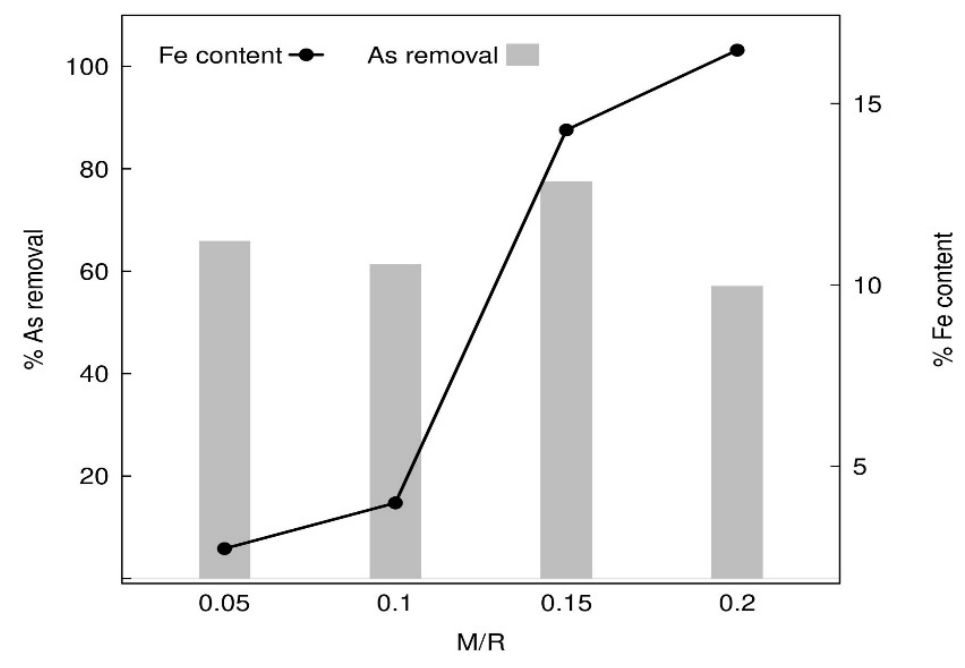

Figure 1. Fe contents on the adsorption of $\mathrm{As}(\mathrm{V})$ using magnetic xerogel monoliths (Conditions: $\mathrm{pH}=5$, contact time $24 \mathrm{~h}$, dose $2 \mathrm{~g} / \mathrm{L}(100 \mathrm{mg} / 50 \mathrm{~mL})$ and As concentration $165 \mu \mathrm{g} / \mathrm{L})$.

\subsection{Characterization of Magnetic Xerogel Monoliths}

\subsubsection{XRD Analysis}

The mineralogical characteristics of MXs were determined by XRD, as shown in Figure 2. The XRD profiles of the MXs with different M/R ratios had similar characterization peak patterns. The patterns of XRD show that MXs contained both of the phase of amorphous and crystalline similarly reported by Oyedoh et al. [22]. The crystalline structure of MXs was composed mainly of magnetite that had similar the diffraction peaks at $2 \theta$ values of $18^{\circ}, 30^{\circ}, 35.5^{\circ}, 43^{\circ}, 57^{\circ}$, and $62^{\circ}$ which were corresponding to $111,220,311$, 400,511 , and 440 of the crystallographic planes of magnetite (ICDD card no. 00-01900629) according to the results of Tipsawat et al. [45]. It can be observed that MXs with low M/R 
ratio had low-intensity and broadened diffraction peaks than MXs with high $M / R$ ratio. Thus, it can be indicated that MXs with high $M / R$ ratio had the crystalline structure.

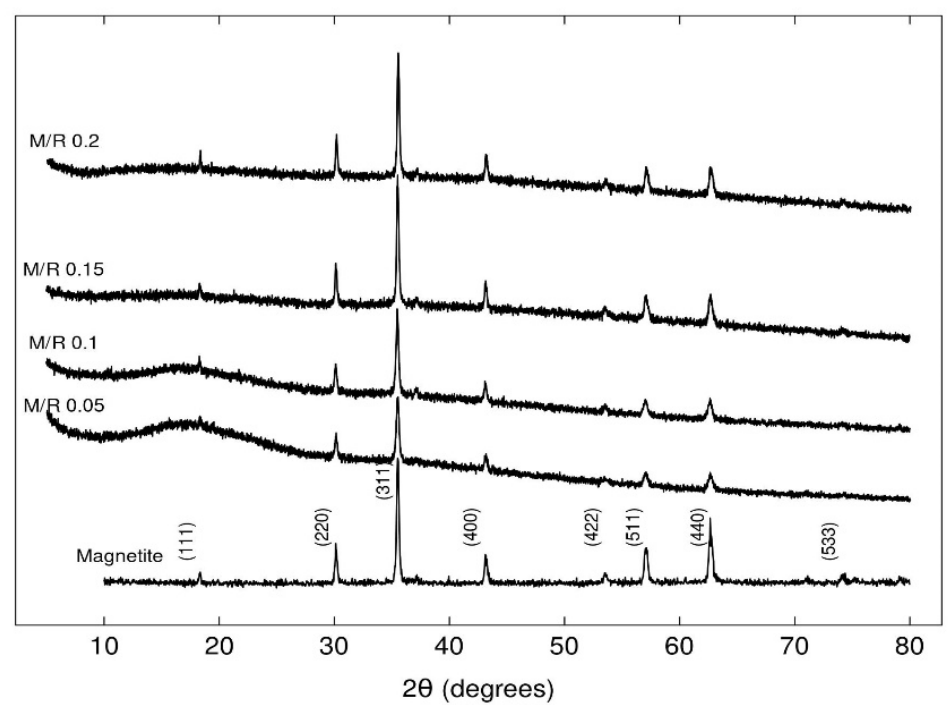

Figure 2. X-ray diffraction patterns of magnetic xerogel monoliths with different molar ratios of M/R.

\subsubsection{SEM Analysis}

The morphology of MXs is presented in Figure 3a that MXs contained connecting microclusters and resulted in a porous structure of RF gels [22,23]. Figure $3 b$ shows that some parts of the surface morphology of MXs had the accumulation that might be caused from the unbound of Fe contents in RF gels before the curing process. It can be explained that magnetite did not cooperate into RF gels and Fe contents in RF gels are a physical dispersion. This finding agrees to the results reported by Verma et al. [29]. Mapping analysis Figure $3 c$ shows the distribution of Fe that was uniformly distributed throughout the RF gels [30]. EDX indicates the elemental composition of an interesting area of MXs sample as shown in Figure 3d. The presence of Fe contents can be confirmed to be approximately $29.75 \%$ within the RF gel.

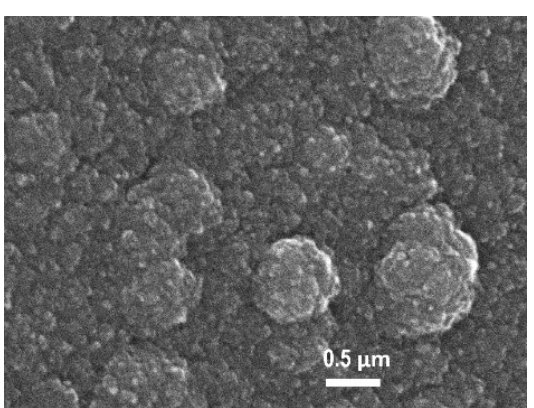

(a)

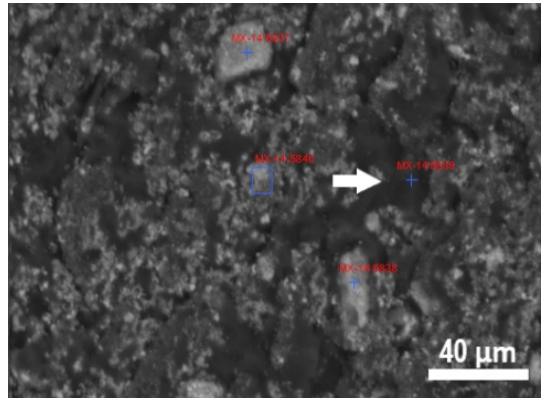

(b)

Figure 3. Cont. 


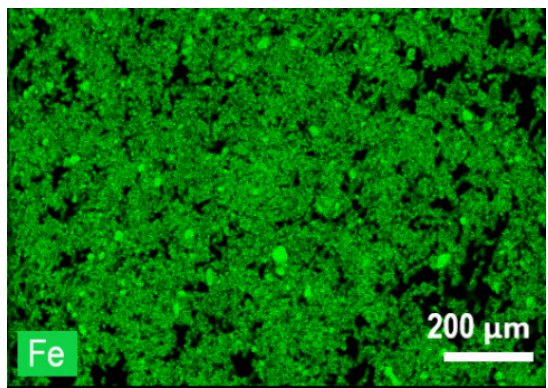

(c)

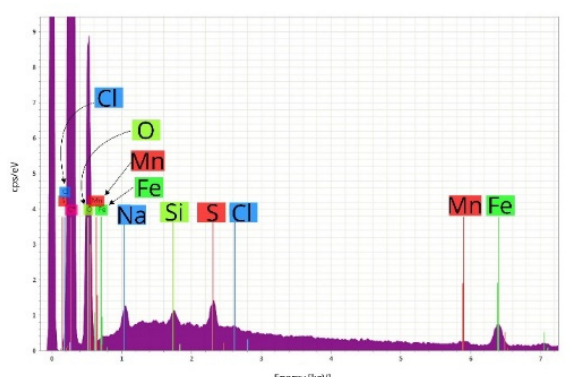

(d)

Figure 3. Scanning Electron Microscopy (SEM) images of magnetic xerogel monoliths (MXs) (a,b), Fe mapping analysis in MXs composites (c) and energy dispersive X-ray analysis (EDX) images with elemental analysis (d) of MXs.

\subsection{3. $\mathrm{pH}_{\mathrm{PZC}}$ and IEP Analysis}

As is well known, the analysis of $\mathrm{pH}_{\mathrm{PZC}}$ and IEP is a technique to determine the nature of the surface chemistry of the adsorbents. The $\mathrm{pH}_{\mathrm{PZC}}$ corresponds to the $\mathrm{pH}$ at which the number of positive and negative charges is equal, so that the total surface charge is zero then the surface of adsorbent is neutral. The $\mathrm{pH}_{\mathrm{PZC}}$ of the MXs was 6.28. Therefore, the positive charge develops on the adsorbent surface of MXs at pH lower 6.28 and the MXs surface becomes negatively charged at $\mathrm{pH}$ above 6.28. IEP is the point that the MXs exhibit no net charge. The IEP of the MXs was 2.1. The surface charge of the composite material is important and influential in the process of the adsorption [30].

\subsubsection{FTIR Analysis}

The FTIR study was used to know the functional groups in the structure of MXs before and after the adsorption of $\mathrm{As}(\mathrm{V})$. The FTIR spectra of MXs samples are plotted and represented in Figure 4. The resultant infrared spectra were acquired and showed the major of six adsorption bands at $3227 \mathrm{~cm}^{-1}$ (-OH group), $2639 \mathrm{~cm}^{-1}$ (C-H stretching), $1605 \mathrm{~cm}^{-1}$ ( $\mathrm{C}=\mathrm{C}$ aromatic stretching), $1464 \mathrm{~cm}^{-1}$ (C-H bending vibration), $1209 \mathrm{~cm}^{-1}$ (C-O stretching), and $548 \mathrm{~cm}^{-1}$ (Fe-O stretching vibration), respectively. The obtained spectra peaks agreed with those of similar reported research $[15,29,46-48]$.

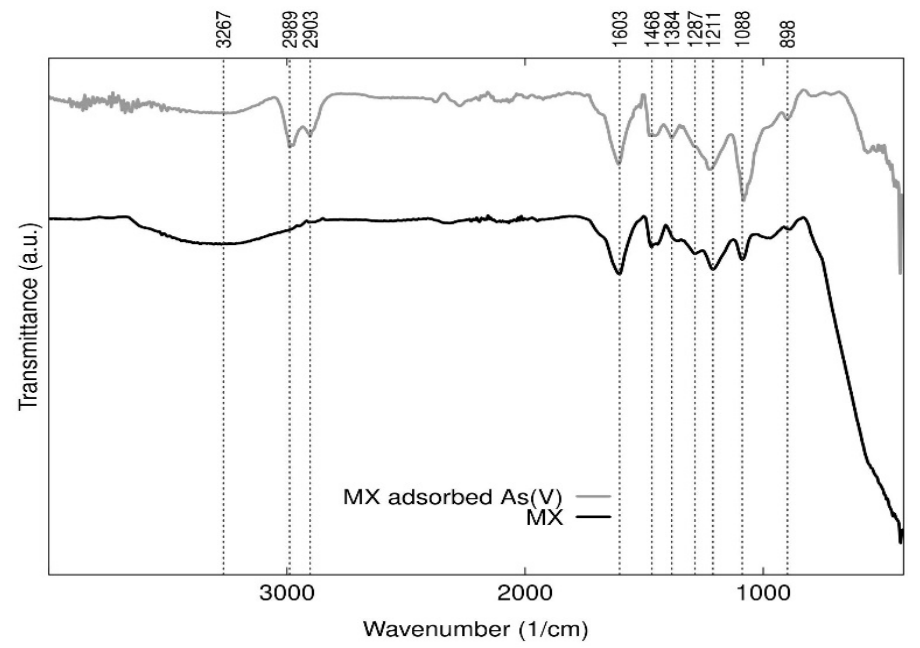

Figure 4. FTIR Spectra of Magnetic Xerogel Monoliths before and after arsenic (V) adsorption.

After As(V) adsorption, a broad band of $\mathrm{OH}$ was shifted to 2989 and $2903 \mathrm{~cm}^{-1}$. It can be explained that the influence of $\mathrm{AsO}_{4}^{3-}$ sorption and thus $\mathrm{OH}$ vibrations around 3300 and $3000 \mathrm{~cm}^{-1}$ developed due to the adsorption and coprecipitation [49]. It can be observed 
that the presence of the new band appeared with small intensity at $898 \mathrm{~cm}^{-1}$ belonging to As-O stretching vibration [50].

\subsection{Arsenic Adsorption Study}

Table 1 presents the properties of physical and chemical groundwater. The values were lower than those established by the official Mexican standard (NOM-127-SSA1-1994). In this study, groundwater was applied as the aqueous medium in the experiment contained natural anions such as $\mathrm{SO}_{4}^{2-}, \mathrm{Cl}^{-}, \mathrm{NO}_{3}^{-}$, and $\mathrm{PO}_{4}^{3-}$ were $37,10.1,4.4$ and $0.82 \mathrm{mg} / \mathrm{L}$, respectively, towards the effect of coexisting ions for the removal of As onto MXs. Mandal et al. [51] described the reduction on arsenic adsorption because of competitive ions by anions $\mathrm{SO}_{4}^{2-}>\mathrm{Cl}^{-}>\mathrm{CO}_{3}^{2-}>\mathrm{HCO}_{3}^{-}>\mathrm{NO}_{3}^{-}$.

Table 1. Characteristic of studied groundwater. All the concentrations are in $\mathrm{mg} / \mathrm{L}$ ( \pm standard deviation).

\begin{tabular}{cccccccccc}
\hline Parameters & $\mathbf{p H}$ & TDS $^{\mathbf{a}}$ & $\mathbf{C l}-$ & Fl- & As & Mn & Fe & NO $_{3}^{-}$ & SO $_{4}^{2-}$ \\
\hline Analysis results & $7.0 \pm 0.5$ & $173 \pm 4$ & $10.4 \pm 0.5$ & $0.25 \pm 0.01$ & 0 & $0.01 \pm 0$ & $0.11 \pm 0.09$ & $4.83 \pm 0.84$ & $34 \pm 2.64$ \\
NOM-127-SSA1-1994 & $6.5-8.5$ & 1000 & 250 & 1.5 & 0.025 & 0.15 & 0.3 & 10 & 400 \\
\hline
\end{tabular}

\subsubsection{Effect of Initial $\mathrm{pH}$ on $\mathrm{As}(\mathrm{V})$ Removal}

The altering of $\mathrm{pH}$ of the solution directly affects and changes the surface chemistry of the adsorbent. The effect of initial $\mathrm{pH}(2-10)$ of $100 \mu \mathrm{g} / \mathrm{L}$ of $\mathrm{As}(\mathrm{V})$ solution on the capacity of adsorption by using magnetic xerogel was investigated, as shown in Figure 5. The percentages of $\mathrm{As}(\mathrm{V})$ removal at different $\mathrm{pH}$ were variable. The maximum of $\mathrm{As}(\mathrm{V})$ removal $(65 \%)$ was observed at $\mathrm{pH}=5$. Percentage of $\mathrm{As}(\mathrm{V})$ removal decreased at $\mathrm{pH}$ $3,4,7$ and 9, which is similar to the results of Khamkure et al. [52]. The percentage of $\mathrm{As}(\mathrm{V})$ removal efficiency of MXs were high values under acidic $(\mathrm{pH}=5)$ and basic $(\mathrm{pH}=8)$ conditions. These results agreed with those reported of Min X. et al. [15] and Wei Z. et al. [53] indicated that the predominant arsenate species are $\mathrm{H}_{2} \mathrm{AsO}_{4}^{-}$should be the major $\mathrm{As}(\mathrm{V})$ species at $\mathrm{pH} 4$ due to the adsorption abilities of arsenic species, water and $\mathrm{OH}^{-}$ follow the order of $\mathrm{AsO}_{4}^{3-}>\mathrm{OH}^{-}>\mathrm{HAsO}_{4}^{2-}>\mathrm{H}_{2} \mathrm{AsO}_{4}^{-}>\mathrm{H}_{3} \mathrm{AsO}_{4}>\mathrm{H}_{2} \mathrm{O}$ for As$(\mathrm{V})$. The observed in the $\mathrm{As}(\mathrm{V})$ adsorption that was low at high $\mathrm{pH}$ solution. It could be explained regarding the increasing repulsion between the increasing of negatively charged $\mathrm{As}(\mathrm{V})$ and negatively charged surface site of iron oxide, and also to an increase in competing of hydroxide ions for adsorption sites [43].

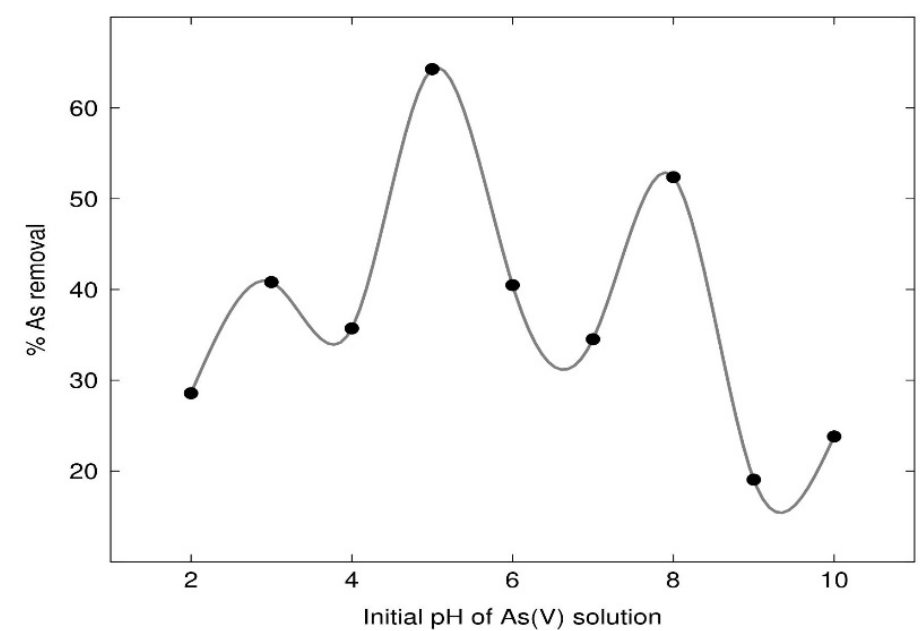

Figure 5. Effect of $\mathrm{pH}$ on the adsorption of $\mathrm{As}(\mathrm{V})$ (Conditions: $\mathrm{pH}=2-10$, contact time $8 \mathrm{~h}$, dose $2 \mathrm{~g} / \mathrm{L}(100 \mathrm{mg} / 50 \mathrm{~mL})$ and As concentration $100 \mu \mathrm{g} / \mathrm{L})$. 


\subsubsection{Effect of Adsorbent Dose on the Removal of $\mathrm{As}(\mathrm{V})$}

In this study, the effect of adsorbent dose on the removal of $\mathrm{As}(\mathrm{V})$ was conducted to determine the optimum mass of adsorbent regarding the adsorptive capacity. The varying of adsorbent doses was $0.5-10 \mathrm{~g} / \mathrm{L}$, in $50 \mathrm{~mL}$ of $100 \mu \mathrm{g} / \mathrm{L}$ of $\mathrm{As}(\mathrm{V})$ solution. The obtained results between adsorbent dose vs $\mathrm{As}(\mathrm{V})$ removal and $\mathrm{q}_{\mathrm{e}}$ are presented in Figure 6. It can be seen that the percentage of $\mathrm{As}(\mathrm{V})$ removal increased from $35 \%$ to $76 \%$ with the increased adsorbent dose from 1 to $2 \mathrm{~g} / \mathrm{L}$ and after that it seems that percentages of As removal (65\%) were relatively constant although the adsorbent dose increased. It can be explained that the particle size of magnetite added into the gels influence the adsorption process due to effective particle size change with increasing adsorbent dose [54]. According to the particle size analysis of magnetite by using Laser Scattering Particle Size Distribution Analyzer (LA-950, Horiba), the mean size was $9.27 \mu \mathrm{m}$ which was larger than average pore diameter of the RF gel which is in the range of the mesopore (approximately $50 \mathrm{~nm}$ ). As in the case of magnetite particle size on the adsorption and desorption, affect the behavior of arsenite and arsenate, the adsorption capacity of arsenite and arsenate increases with decreasing magnetite particle size described by Yean et al. [55].

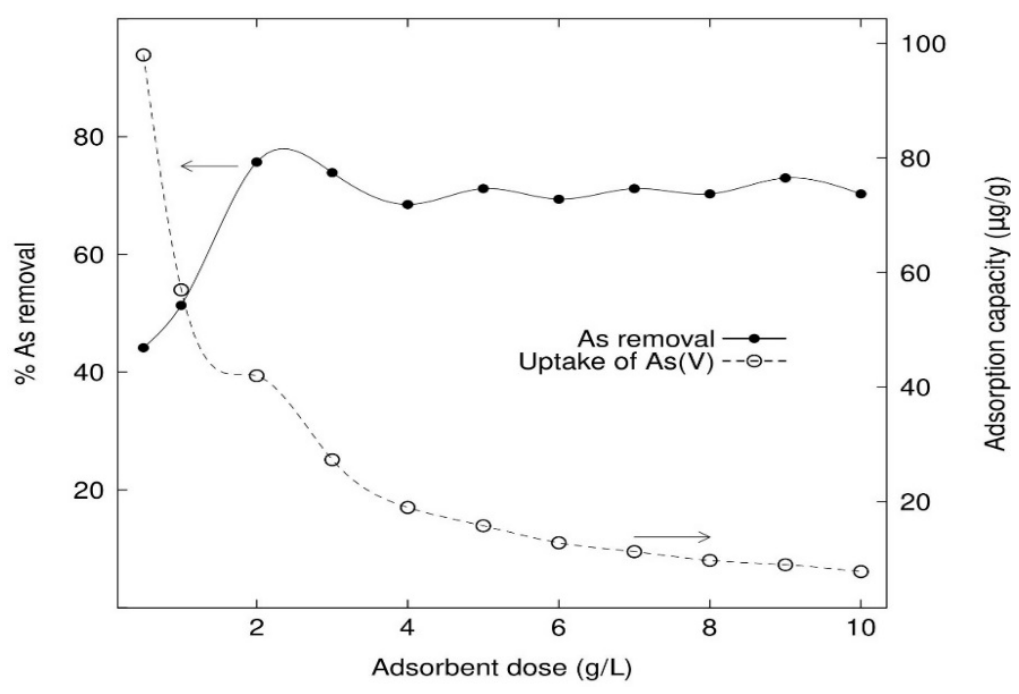

Figure 6. Effect of adsorbent dose on the adsorption of $\mathrm{As}(\mathrm{V})$ (Conditions: $\mathrm{pH}=5$, contact time $24 \mathrm{~h}$, As concentration $100 \mu \mathrm{g} / \mathrm{L}$ and temperature $25^{\circ} \mathrm{C}$ ).

\subsection{Kinetic Adsorption Models}

In order to understand the reaction pathway and the mechanism of adsorption process, the change of the amount of $\mathrm{As}(\mathrm{V})$ on solution that was removed following the adsorption time, were observed until reach to the equilibrium. Several kinetic models were used to determine the constant of kinetic adsorption. É.C. Lima et al. [56] summarized kinetic models based on the order of reaction and the most used for adsorption analysis are a pseudo first order (PFO) and pseudo second order (PSO) kinetic adsorption models. Therefore, four kinetic models PFO, PSO, Elovich and Power function were applied to fit the kinetic data by non-linear regression to describe the $\mathrm{As}(\mathrm{V})$ adsorption with $\mathrm{MXs}$ adsorbent, as follows [57]:

$$
\begin{gathered}
\text { Pseudo first-order equation : } q_{t}=q_{e}\left(1-e^{-k_{1} t}\right) \\
\text { Pseudo second-order model : } q_{t}=\frac{k_{2} q_{e}^{2} t}{1+k_{2} q_{e} t} \\
\text { Elovich }: q_{t}=\frac{1}{\beta} \ln (\alpha \beta)+\frac{1}{\beta} \ln (t)
\end{gathered}
$$




$$
\text { Power function : } q_{t}=a t^{b}
$$

where $q_{t}$ and $q_{e}$ are the amount of $\mathrm{As}(\mathrm{V})$ adsorbed at time $t(\mathrm{mg} / \mathrm{g})$ and the equilibrium adsorption capacity $(\mathrm{mg} / \mathrm{g})$, respectively. $\mathrm{k}_{1}$ and $\mathrm{k}_{2}$ are the pseudo first-order rate constant $\left(\mathrm{min}^{-1}\right)$ and the pseudo second-order rate constant $\left(\mathrm{min}^{-1}\right)$, respectively and $t$ is the contact time $(\mathrm{min}) . \alpha(\mathrm{mg} / \mathrm{g} \mathrm{min})$ is a constant related to chemisorption rate and $\beta(\mathrm{g} / \mathrm{mg})$ is a constant of the extent of surface coverage, finally $a$ and $b$ are constants.

A non-linear regression analysis was used to compute the experimental data and solve the adsorption kinetic models. The adsorption kinetics study with four kinetic models PFO, PSO, Elovich, and Power function are shown in Figure 7 and the corresponding parameter estimates and correlation coefficients are presented in Table 2. It can be observed that the Elovich equation was best described on $\mathrm{As}(\mathrm{V})$ adsorption data due to higher $\mathrm{R}^{2}$ value (0.94), and lower RSS and RMSE values that are considered to represent goodness of conformity. The Elovich equation is generally applied to chemisorption kinetic for adsorbing to heterogeneous surfaces and has covered a wide range of slow adsorption rates [56]. Due to the result of kinetics of liquid phase batch adsorption experiments, it presents the slow stage of $\mathrm{As}(\mathrm{V})$ adsorption following an Elovich equation. This result agrees with a study reported by Zhang and Stanforth [54] indicating that may be caused by the heterogeneity of surface binding sites or other reactions for the removal of arsenic. Moreover, the equilibrium adsorption was fitted well to the power function equation $\left(R^{2}=0.92\right)$. The $R^{2}$ values were relatively lower for the pseudo second-order equation $(0.75)$ and the pseudo first-order equation (0.50).

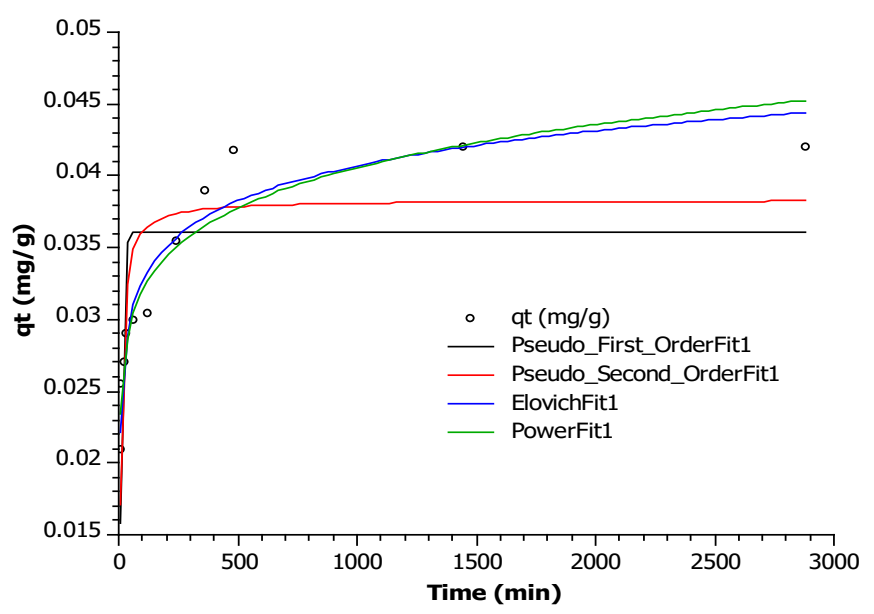

Figure 7. Adsorption kinetics study with several models for $\mathrm{As}(\mathrm{V})$ (Conditions: $\mathrm{pH}=5$, dose $2 \mathrm{~g} / \mathrm{L}$ $(100 \mathrm{mg} / 50 \mathrm{~mL})$, As concentration $100 \mu \mathrm{g} / \mathrm{L}$ and temperature $\left.25^{\circ} \mathrm{C}\right)$.

Table 2. Estimation the kinetic model parameters and correlation coefficients for As(V) adsorption by Magnetic Xerogel Monoliths.

\begin{tabular}{|c|c|c|c|c|c|}
\hline Pseudo first-order equation & $\begin{array}{c}k_{1} \\
0.1152\end{array}$ & $\begin{array}{c}\mathrm{q}_{\mathrm{t}}(\mu \mathrm{g} / \mathrm{g}) \\
36.12\end{array}$ & $\begin{array}{c}R^{2} \\
0.5043\end{array}$ & $\begin{array}{c}\text { RMSE } \\
5.50 \times 10^{-3}\end{array}$ & $\begin{array}{c}\text { RSS } \\
2.72 \times 10^{-4}\end{array}$ \\
\hline Pseudo second-order equation & $\begin{array}{c}\mathbf{k}_{\mathbf{2}} \\
4.1868\end{array}$ & $\begin{array}{c}\mathrm{q}_{\mathrm{t}}(\mu \mathrm{g} / \mathrm{g}) \\
38.32\end{array}$ & $\begin{array}{c}\mathbf{R}^{\mathbf{2}} \\
0.7477\end{array}$ & $\begin{array}{c}\text { RMSE } \\
3.92 \times 10^{-3}\end{array}$ & $\begin{array}{c}\text { RSS } \\
1.38 \times 10^{-4}\end{array}$ \\
\hline Elovich equation & $\begin{array}{c}\alpha(\mathrm{mg} / \mathrm{g} \text { min }) \\
0.38\end{array}$ & $\begin{array}{c}\beta(\mathrm{g} / \mathrm{mg}) \\
284.6\end{array}$ & $\begin{array}{c}\mathbf{R}^{\mathbf{2}} \\
0.9391\end{array}$ & $\begin{array}{c}\text { RMSE } \\
1.93 \times 10^{-3}\end{array}$ & $\begin{array}{c}\text { RSS } \\
3.34 \times 10^{-5}\end{array}$ \\
\hline Power function equation & $\begin{array}{c}\mathbf{a} \\
0.0199\end{array}$ & $\begin{array}{c}\mathbf{b} \\
0.1032\end{array}$ & $\begin{array}{c}\mathbf{R}^{\mathbf{2}} \\
0.9171\end{array}$ & $\begin{array}{c}\text { RMSE } \\
2.25 \times 10^{-3}\end{array}$ & $\begin{array}{c}\text { RSS } \\
4.55 \times 10^{-5}\end{array}$ \\
\hline
\end{tabular}




\subsection{Adsorption Isotherm}

The adsorption isotherm is the relation of amount of solute adsorbed per unit of the adsorbents reaching to the equilibrium concentration at the constant temperature. Several models can be applied to describe the experimental adsorption data and the most common models like Langmuir and Freundlich equations are widely used for adsorption isotherm.

The Langmuir isotherm considers sorption as a chemical phenomenon and describes the monolayer adsorption of a solute onto a homogeneous surface with a finite number of similar active sites. The Freundlich isotherm describes multilayer adsorption on the heterogeneous surface having a non-uniform energy distribution of the active sites [29,44]. Therefore, Langmuir and Freundlich isotherm models were applied to fit the isotherm data by non-linear regression to describe the relative $\mathrm{As}(\mathrm{V})$ concentrations adsorbed to $\mathrm{MXs}$ adsorbent as follows [57]:

$$
\begin{gathered}
\text { Langmuir isotherm : } \mathrm{q}_{\mathrm{e}}=\frac{\mathrm{b} \mathrm{qmCe}}{(1+\mathrm{bCe})} \\
\text { Freundlich isotherm : } \mathrm{q}_{\mathrm{e}}=\mathrm{KCe}^{\frac{1}{n}}
\end{gathered}
$$

where $\mathrm{q}_{\mathrm{e}}$ is the amount of $\mathrm{As}(\mathrm{V})$ ions adsorbed by the adsorbent $(\mathrm{mg} / \mathrm{g})$, Ce is the equilibrium concentration of adsorbate in solution $(\mathrm{mg} / \mathrm{L}), \mathrm{q}_{\mathrm{m}}$ is the maximum adsorption capacity $(\mathrm{mg} / \mathrm{g})$, and $\mathrm{b}$ is the Langmuir constant that is related to the energy of adsorption $(\mathrm{L} / \mathrm{mg}) . \mathrm{K}$ and $\mathrm{n}$ are Freundlich constants indicating the measurement of the adsorption capacity and intensity, respectively.

The adsorption isotherm for $\mathrm{As}(\mathrm{V})$ removal using MXs, was studied by varying $\mathrm{As}(\mathrm{V})$ solution with different concentrations (25-175 $\mu \mathrm{g} / \mathrm{L})$ and the fixed of MXs dose (2 g/L) at $25^{\circ} \mathrm{C}$. The plot of $\mathrm{q}_{\mathrm{e}}$ versus $\mathrm{Ce}$ of $\mathrm{As}(\mathrm{V})$ adsorption can be determined parameters of the isotherm models [41]. The Langmuir and Freundlich isotherms for $\mathrm{As}(\mathrm{V})$ adsorption is presented in Figure 8. It can be observed that the adsorption capacity of As(V) increased with the increase of the $\mathrm{As}(\mathrm{V})$ concentration. The isotherm parameters and the correlation coefficients are shown in Table 3. It can be observed that a similar value of $R^{2}$ was found for Langmuir and Freundlich isotherm, corresponding to the results reported by Perdigoto et al. [35]. Furthermore, the Freundlich model indicated as a better fit to describe the experimental equilibrium data of $\mathrm{As}(\mathrm{V})$ adsorption using $\mathrm{MXs}$ due to the higher value of $R^{2}$. It is apparent that the $\mathrm{As}(\mathrm{V})$ adsorption is similar to having the adsorption onto a heterogeneous surface rather than monolayer adsorption. This result was in good agreement with the study of adsorption kinetic as discussed above that the slow stage of arsenate adsorption follows an Elovich equation due to the heterogeneity of the surface.

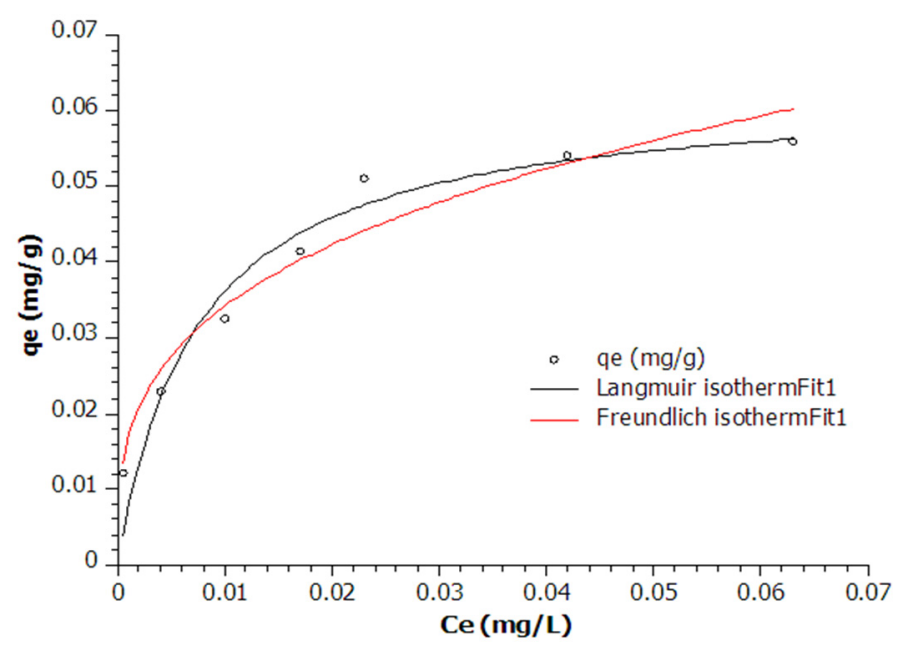

Figure 8. The Langmuir and Freundlich isotherms for $\mathrm{As}(\mathrm{V})$ adsorption (Conditions: $\mathrm{pH}=5$, dose $2 \mathrm{~g} / \mathrm{L}(100 \mathrm{mg} / 50 \mathrm{~mL})$ and temperature $\left.25^{\circ} \mathrm{C}\right)$. 
Table 3. Parameters of the Langmuir and Freundlich isotherm models for As(V) adsorption on Magnetic Xerogel Monoliths.

\begin{tabular}{cccccc}
\hline & Langmuir & \multicolumn{3}{c}{ Freundlich } \\
\hline $\mathbf{q}_{\mathbf{m}}(\boldsymbol{\mu g} / \mathbf{g})$ & $\mathbf{b}(\mathbf{L} / \mathbf{m g})$ & $\mathbf{R}^{\mathbf{2}}$ & $\mathbf{K}$ & $\mathbf{n}$ & $\mathbf{R}^{\mathbf{2}}$ \\
\hline 62.82 & 135.6 & 0.9404 & 0.1409 & 3.25 & 0.9528 \\
\hline
\end{tabular}

\subsection{Adsorption Thermodynamics}

In this experiment, adsorption thermodynamics were studied to understand the effect on $\mathrm{As}(\mathrm{V})$ adsorption process with different temperatures at 298, 308, and $318 \mathrm{~K}$. The thermodynamic parameters are the changes of Gibb's free $(\Delta \mathrm{G})$, entropy of the adsorption $(\Delta \mathrm{S})$, and enthalpy of adsorption $(\Delta \mathrm{H})$. According to the van't Hoff equation, $\Delta \mathrm{G}, \Delta \mathrm{S}$ and $\Delta \mathrm{H}$ of the experimental data were calculated as follow:

$$
\begin{gathered}
\Delta \mathrm{G}=-\operatorname{RTIn}\left(\mathrm{K}_{\mathrm{D}}\right) \\
\Delta \mathrm{G}=\Delta \mathrm{H}-\mathrm{T} \Delta \mathrm{S} \\
\ln \left(\mathrm{K}_{\mathrm{D}}\right)=-\frac{\Delta \mathrm{H}}{\mathrm{RT}}+\frac{\Delta \mathrm{S}}{\mathrm{R}}
\end{gathered}
$$

where $R$ is the universal gas constant, $T$ is the absolute temperature and $K_{D}$ is the equilibrium constant.

The results of the calculation of the thermodynamic parameters for $\mathrm{As}(\mathrm{V})$ adsorption on MXs are shown in Table 4. A negative value of $\Delta \mathrm{G}$ indicates that the adsorption of $\operatorname{As}(\mathrm{V})$ by MXs is a spontaneous process. The positive value of $\Delta \mathrm{H}$ demonstrates the endothermic nature of the adsorption process. The value of $\Delta \mathrm{S}$ was positive. Not only it reflects the affinity adsorption of the MXs toward $\mathrm{As}(\mathrm{V})$ and may affect to the change of the structure in the arsenic species and the adsorbent, but also it indicates the increasing of randomness at the solid and liquid interface during $\mathrm{As}(\mathrm{V})$ adsorption on the MXs [43].

Table 4. Thermodynamic parameters for As(V) adsorption on Magnetic Xerogel Monoliths.

\begin{tabular}{cccc}
\hline Temperature (K) & DG (KJ/mol) & DH (KJ/mol) & DS (J/mol) \\
\hline 298 & -6.051 & 17.949 & 79.902 \\
308 & -6.255 & & \\
318 & -7.676 & & \\
\hline
\end{tabular}

\subsection{Desorption Study}

In this study, $1 \mathrm{M} \mathrm{KOH}$ solution was employed to promote the desorption of used adsorbent over 90 and $180 \mathrm{~min}$ with centrifuge at $200 \mathrm{rpm}$. It can be observed that the desorption efficiency of used MXs with centrifugation time $180 \mathrm{~min}(70 \%)$ was higher than centrifugation time $90 \mathrm{~min}(45 \%)$ [37]. This result indicates that this adsorbent had ability and potential for As removal in the practical application. Therefore, additional studies should be conducted to investigate the method and condition of regenerability and lifetime of the adsorbent to have good performance on arsenic removal and least environmental impact.

\section{Conclusions}

The synthesized magnetic xerogel monoliths ( $14.27 \%$ of Fe contents) with molar ratio of magnetite and resorcinol at 0.15 was applied for $\mathrm{As}(\mathrm{V})$ removal from groundwater. Magnetite was incorporated in the structure of RF gels corresponding to XRD patterns and SEM figures that was physical without participation in the polycondensation reaction of RF. $\mathrm{pH}$ in groundwater $(\mathrm{pH}=5)$ with MXs dose $(2 \mathrm{~g} / \mathrm{L})$ and particle size of magnetite in RF gels play an important role in $\mathrm{As}(\mathrm{V})$ adsorption. Adsorption kinetics of $\mathrm{As}(\mathrm{V})$ on MXs was better described by the Elovich equation, followed by the power function equation, 
the PSO equation and then the PFO equation. The experimental data was correlated to the Freundlich isotherm. Thermodynamic study confirmed that the adsorption process is endothermic and spontaneous in nature due to negative value of free energy change and positive value of enthalpy change. Desorption results showed that the desorption efficiency was $70 \%$.

Author Contributions: Conceptualization, S.E.G.-H. and S.K.; methodology, S.K.; software, A.R.R.; formal analysis, S.K.; investigation, S.K.; resources, S.E.G.-H. and P.G.-M.; writing-original draft preparation, S.K.; writing — review and editing, S.E.G.-H. and P.G.-M.; visualization, A.R.-R.; supervision, S.E.G.-H. and P.G.-M. All authors have read and agreed to the published version of the manuscript.

Funding: This research received no external funding.

Acknowledgments: Khamkure S. acknowledges for the financial support by the National Council of Science and Technology (CONACyT), Mexico under the program Catedras-CONACyT with project no. 159. Authors would like to thank Oscar Talavera Mendoza and Jazmin A. López Díaz for the technical analysis.

Conflicts of Interest: The authors declare no conflict of interest.

\section{References}

1. Armienta, M.A.; Segovia, N. Arsenic and fluoride in the groundwater of Mexico. Environ. Geochem. Health 2008, 30, 345-353. [CrossRef]

2. Garelick, H.; Jones, H.; Dybowska, A.; Valsami-Jones, E. Arsenic pollution sources. Rev. Environ. Contam. Toxicol. 2009, 197, 17-60. [CrossRef]

3. Lata, S.; Samadder, S. Removal of arsenic from water using nano adsorbents and challenges: A review. J. Environ. Manag. 2016, 166, 387-406. [CrossRef] [PubMed]

4. Pal, P.; Sen, M.; Manna, A.; Pal, J.; Pal, P.; Roy, S.; Roy, P. Contamination of groundwater by arsenic: A review of occurrence, causes, impacts, remedies and membrane-based purification. J. Integr. Environ. Sci. 2009, 6, 295-316. [CrossRef]

5. Shankar, S.; Shanker, U.; Shikha. Arsenic contamination of groundwater: A review of sources, prevalence, health risks, and strategies for mitigation. Sci. World J. 2014, 2014. [CrossRef]

6. $\quad$ Ettinger, A.S.; Arbuckle, T.E.; Fisher, M.; Liang, C.L.; Davis, K.; Cirtiu, C.-M.; Bélanger, P.; Leblanc, A.; Fraser, W.D. Arsenic levels among pregnant women and newborns in Canada: Results from the Maternal-Infant Research on Environmental Chemicals (MIREC) cohort. Environ. Res. 2017, 153, 8-16. [CrossRef] [PubMed]

7. Limón-Pacheco, J.H.; Jiménez-Córdova, M.I.; Cárdenas-González, M.; Retana, I.M.S.; Gonsebatt, M.E.; Del Razo, L.M. Potential co-exposure to arsenic and fluoride and biomonitoring equivalents for Mexican children. Ann. Glob. Health 2018, 84, $257-273$. [CrossRef]

8. Hurtado-Jiménez, R.; Gardea-Torresdey, J.L. Arsenic in drinking water in the Los Altos de Jalisco region of Mexico. Rev. Panam. Salud Pública 2006, 20, 236-247. [CrossRef]

9. Elcik, H.; Celik, S.O.; Cakmakci, M.; Özkaya, B. Performance of nanofiltration and reverse osmosis membranes for arsenic removal from drinking water. Desalination Water Treat. 2015, 57, 20422-20429. [CrossRef]

10. Vithanage, M.; Dabrowska, B.B.; Mukherjee, A.B.; Sandhi, A.; Bhattacharya, P. Arsenic uptake by plants and possible phytoremediation applications: A brief overview. Environ. Chem. Lett. 2011, 10, 217-224. [CrossRef]

11. Hoyos, S.E.G.; Flores, M.A.; Gonzalez, A.R.; Fajardo, C.G.; Zoloeta, S.C.; Orozco, H.V. Comparing two operating configurations in a full-scale arsenic removal plant. Case study: Guatemala. Water 2013, 5, 834-851. [CrossRef]

12. Ozkula, G.; Urbano, B.F.; Rivas, B.L.; Kabay, N.; Bryjak, M. Arsenic sorption using mixtures of ion exchange resins containing n-methyl-d-glucamine and quaternary ammonium groups. J. Chil. Chem. Soc. 2016, 61, 2752-2756. [CrossRef]

13. Urbano, B.F.; Rivas, B.L.; Martínez, F.; Alexandratos, S.D. Water-insoluble polymer-clay nanocomposite ion exchange resin based on N-methyl-d-glucamine ligand groups for arsenic removal. React. Funct. Polym. 2012, 72, 642-649. [CrossRef]

14. Karimi, P.; Javanshir, S.; Sayadi, M.H.; Arabyarmohammadi, H. Arsenic removal from mining effluents using plant-mediated, green-synthesized iron nanoparticles. Processes 2019, 7, 759. [CrossRef]

15. Min, X.; Li, Y.; Ke, Y.; Shi, M.; Chai, L.; Xue, K. Fe-FeS 2 adsorbent prepared with iron powder and pyrite by facile ball milling and its application for arsenic removal. Water Sci. Technol. 2017, 76, 192-200. [CrossRef]

16. Yao, S.; Liu, Z.; Shi, Z. Arsenic removal from aqueous solutions by adsorption onto iron oxide/activated carbon magnetic composite. J. Environ. Health Sci. Eng. 2014, 12, 58. [CrossRef]

17. Bonilla-Petriciolet, A.; Mendoza-Castillo, D.I.; Reynel-Ávila, H.E. Adsorption Processes for Water Treatment and Purification, 1st ed.; Springer International Publishing: Cham, Switzerland, 2017; ISBN 9783319581361.

18. Pekala, R.W. Organic aerogels from the polycondensation of resorcinol with formaldehyde. J. Mater. Sci. 1989, $24,3221-3227$. [CrossRef] 
19. Al-Muhtaseb, S.; Ritter, J. Preparation and properties of resorcinol-formaldehyde organic and carbon gels. Adv. Mater. 2003, 15, 101-114. [CrossRef]

20. Khamkure, S.; Treesatayapun, C.; Garrido-Hoyos, S.E.; Gamero-Melo, P.; Reyes-Rosas, A. Prediction of the pH effect on arsenic (V) removal by varying catalyst of magnetic xerogel monoliths based on FREN model. Water Supply 2020, 20, 2747-2761. [CrossRef]

21. Mirzaeian, M.; Hall, P.J. The control of porosity at nano scale in resorcinol formaldehyde carbon aerogels. J. Mater. Sci. 2009, 44, 2705-2713. [CrossRef]

22. Oyedoh, E.A.; Albadarin, A.B.; Walker, G.M.; Mirzaeian, M.; Ahmad, M.N.M. Preparation of controlled porosity resorcinol formaldehyde xerogels for adsorption applications. Chem. Eng. Trans. 2013, 32, 1651-1656. [CrossRef]

23. Prostredný, M.; Abduljalil, M.G.M.; Mulheran, P.A.; Fletcher, A.J. Process variable optimization in the manufacture of resorcinolformaldehyde gel materials. Gels 2018, 4, 36. [CrossRef] [PubMed]

24. Moreno-Castilla, C.; Maldonado-Hódar, A.F.J.; Pérez-Cadenas, A. Physicochemical surface properties of Fe, Co, Ni, and Cu-doped monolithic organic aerogels. Langmuir 2003, 19, 5650-5655. [CrossRef]

25. Łuzny, R.; Ignasiak, M.; Walendziewski, J.; Stolarski, M. Heavy metal ions removal from aqueous solutions using carbon aerogels and xerogels. Chemik 2014, 68, 544-553.

26. Huang, G.; Li, W.; Song, Y. Preparation of $\mathrm{SiO}_{2}-\mathrm{ZrO}_{2}$ xerogel and its application for the removal of organic dye. J. Sol-Gel Sci. Technol. 2018, 86, 175-186. [CrossRef]

27. Vivo-Vilches, J.F.; Pérez-Cadenas, A.F.; Maldonado-Hódar, F.J.; Carrasco-Marin, F.; Regufe, M.J.; Ribeiro, A.M.; Ferreira, A.F.P.; Rodrigues, A.E. Resorcinol-formaldehyde carbon xerogel as selective adsorbent of carbon dioxide present on biogas. Adsorption 2018, 24, 169-177. [CrossRef]

28. Haro, M.; Rasines, G.; Macias, C.; Ania, C. Stability of a carbon gel electrode when used for the electro-assisted removal of ions from brackish water. Carbon 2011, 49, 3723-3730. [CrossRef]

29. Verma, N.K.; Khare, P.; Verma, N. Synthesis of iron-doped resorcinol formaldehyde-based aerogels for the removal of Cr(VI) from water. Green Process. Synth. 2015, 4, 37-46. [CrossRef]

30. Minovic-Arsic, T.; Kalijadis, A.; Matovic, B.; Stoiljkovic, M.; Pantic, J.; Jovanovic, J.; Petrovic, R.; Jokic, B.; Babic, B. Arsenic(III) adsorption from aqueous solutions on novel carbon cryogel/ceria nanocomposite. Process. Appl. Ceram. 2016, 10, 17-23. [CrossRef]

31. Maldonado-Hódar, F.J. Advances in the development of nanostructured catalysts based on carbon gels. Catal. Today 2013, 218-219, 43-50. [CrossRef]

32. Ribeiro, R.S.; Frontistis, Z.; Mantzavinos, D.; Venieri, D.; Antonopoulou, M.; Konstantinou, I.; Silva, A.M.; Faria, J.L.; Gomes, H.T. Magnetic carbon xerogels for the catalytic wet peroxide oxidation of sulfamethoxazole in environmentally relevant water matrices. Appl. Catal. B Environ. 2016, 199, 170-186. [CrossRef]

33. Morales-Torres, S.; Jirglová, H.; Pastrana-Martínez, L.M.; Maldonado-Hódar, F.J. Influence of electrostatic interactions during the resorcinol-formaldehyde polymerization on the characteristics of mo-doped carbon gels. Processes 2020, 8, 746. [CrossRef]

34. Moreno-Castilla, C.; Maldonado-Hódar, F. Carbon aerogels for catalysis applications: An overview. Carbon 2005, 43, 455-465. [CrossRef]

35. Perdigoto, M.; Martins, R.; Rocha, N.; Quina, M.; Gando-Ferreira, L.; Patrício, R.; Durães, L. Application of hydrophobic silica based aerogels and xerogels for removal of toxic organic compounds from aqueous solutions. J. Colloid Interface Sci. 2012, 380, 134-140. [CrossRef]

36. Fathy, N.A.; Rizk, M.S.; Awad, R.M. Pore structure and adsorption properties of carbon xerogels derived from carbonization of tannic acid-resorcinol-formaldehyde resin. J. Anal. Appl. Pyrolysis 2016, 119, 60-68. [CrossRef]

37. Gore, P.; Khraisheh, M.; Kandasubramanian, B. Nanofibers of resorcinol-formaldehyde for effective adsorption of As (III) ions from mimicked effluents. Environ. Sci. Pollut. Res. 2018, 25, 11729-11745. [CrossRef] [PubMed]

38. Job, N.; Pirard, R.; Marien, J.; Pirard, J.-P. Synthesis of transition metal-doped carbon xerogels by solubilization of metal salts in resorcinol-formaldehyde aqueous solution. Carbon 2004, 42, 3217-3227. [CrossRef]

39. Amaringo, F.A.; Anaguano, A. Determinación del punto de carga cero y punto isoeléctrico de dos residuos agrícolas y su aplicación en la remoción de colorantes. Rev. Investig. Agrar. Ambient. 2013, 4, 27-36. [CrossRef]

40. APHA. Standard Methods for the Examination of Water and Waste Water; American Public Health Association: Washington, DC, USA, 1998.

41. López-Luna, J.; Ramírez-Montes, L.E.; Martinez-Vargas, S.; Martínez, A.I.; Mijangos-Ricardez, O.F.; González-Chávez, M.D.C.A.; Carrillo-González, R.; Solís-Domínguez, F.A.; Cuevas-Díaz, M.D.C.; Vázquez-Hipólito, V. Linear and nonlinear kinetic and isotherm adsorption models for arsenic removal by manganese ferrite nanoparticles. SN Appl. Sci. 2019, 1. [CrossRef]

42. Van Dang, S.; Kawasaki, J.; Abella, L.C.; Auresenia, J.; Habaki, H.; Gaspillo, P.-A.D.; Kosuge, H.; Doan, H.T. Removal of arsenic from simulated groundwater by adsorption using iron-modified rice husk carbon. J. Water Environ. Technol. 2009, 7, 43-56. [CrossRef]

43. Zeng, L. Arsenic adsorption from aqueous solutions on an Fe(III)-Si binary oxide adsorbent. Water Qual. Res. J. 2004, 39, 267-275. [CrossRef]

44. Hanbali, M.; Holail, H.; Hammud, H. Remediation of lead by pretreated red algae: Adsorption isotherm, kinetic, column modeling and simulation studies. Green Chem. Lett. Rev. 2014, 7, 342-358. [CrossRef] 
45. Tipsawat, P.; Wongpratat, U.; Phumying, S.; Chanlek, N.; Chokprasombat, K.; Maensiri, S. Magnetite $\left(\mathrm{Fe}_{3} \mathrm{O}_{4}\right)$ nanoparticles: Synthesis, characterization and electrochemical properties. Appl. Surf. Sci. 2018, 446, 287-292. [CrossRef]

46. Attia, S.M.; Abdelfatah, M.S.; Mossad, M.M. Conduction mechanism and dielectric properties of pure and composite resorcinol formaldehyde aerogels doped with silver. J. Phys. Conf. Ser. 2017, 869, 12035. [CrossRef]

47. Morales-Torres, S.; Maldonado-Hódar, F.J.; Pérez-Cadenas, A.; Carrasco-Marín, F. Textural and mechanical characteristics of carbon aerogels synthesized by polymerization of resorcinol and formaldehyde using alkali carbonates as basification agents. Phys. Chem. Chem. Phys. 2010, 12, 10365-10372. [CrossRef]

48. Taleb, K.; Markovski, J.; Veličković, Z.; Rusmirović, J.; Rančić, M.; Pavlović, V.; Marinković, A. Arsenic removal by magnetiteloaded amino modified nano/microcellulose adsorbents: Effect of functionalization and media size. Arab. J. Chem. 2019, 12, 4675-4693. [CrossRef]

49. Myneni, S.C.; Traina, S.J.; Waychunas, G.A.; Logan, T.J. Vibrational spectroscopy of functional group chemistry and arsenate coordination in ettringite. Geochim. Cosmochim. Acta 1998, 62, 3499-3514. [CrossRef]

50. Yu, X.; Wei, Y.; Liu, C.; Ma, J.; Liu, H.; Wei, S.; Deng, W.; Xiang, J.; Luo, S. Ultrafast and deep removal of arsenic in highconcentration wastewater: A superior bulk adsorbent of porous $\mathrm{Fe}_{2} \mathrm{O}_{3}$ nanocubes-impregnated graphene aerogel. Chemosphere 2019, 222, 258-266. [CrossRef]

51. Mandal, S.; Sahu, M.K.; Patel, R.K. Adsorption studies of arsenic(III) removal from water by zirconium polyacrylamide hybrid material (ZrPACM-43). Water Resour. Ind. 2013, 4, 51-67. [CrossRef]

52. Khamkure, S.; Treesatayapun, C.; Garrido-Hoyos, S.E.; Gamero-Melo, P.; Reyes-Rosas, A. Textural properties of Magnetic Xerogel monoliths and its Prediction of the Effect of $\mathrm{pH}$ on Arsenic (V) adsorption. In Proceedings of the 2019 International Conference on Engineering, Science, and Industrial Applications, ICESI 2019, Tokyo, Japan, 22-24 August 2019; pp. 111-116. [CrossRef]

53. Wei, Z.; Liang, K.; Wu, Y.; Zou, Y.; Zuo, J.; Arriagada, D.C.; Pan, Z.; Hu, G. The effect of pH on the adsorption of arsenic(III) and arsenic(V) at the $\mathrm{TiO}_{2}$ anatase [101] surface. J. Colloid Interface Sci. 2016, 462, 252-259. [CrossRef]

54. Zhang, J.; Stanforth, R. Slow adsorption reaction between arsenic species and goethite ( $\alpha$-FeOOH): Diffusion or heterogeneous surface reaction control. Langmuir 2005, 21, 2895-2901. [CrossRef] [PubMed]

55. Yean, S.; Cong, L.; Yavuz, C.T.; Mayo, J.T.; Yu, W.W.; Kan, A.T.; Colvin, V.L.; Tomson, M.B. Effect of magnetite particle size on adsorption and desorption of arsenite and arsenate. J. Mater. Res. 2005, 20, 3255-3264. [CrossRef]

56. Lima, É.C.; Adebayo, M.A.; Machado, F.M. Kinetic and equilibrium models of adsorption. Carbon Nanostruct. 2015, 33-69. [CrossRef]

57. Malekian, R.; Abedi-Koupai, J.; Eslamian, S.S.; Mousavi, S.F.; Abbaspour, K.C.; Afyuni, M. Ion-exchange process for ammonium removal and release using natural Iranian zeolite. Appl. Clay Sci. 2011, 51, 323-329. [CrossRef] 